\title{
A Research on the Adaptation Translation Strategies of the Culture-loaded Words from the Perspective of the Intercultural Communication
}

\author{
Yong Qin ${ }^{1, *}$ \\ ${ }^{I}$ School of Humanities and Social Sciences, Xi'an Polytechnic University, Xi'an, Shaanxi, China \\ "Email:1724420647@qq.com
}

\begin{abstract}
The translation quality of the culture-loaded words of the Chinese literary work plays a significant role in the intercultural communication between China and the West. With Howard Goldblatt's translation of Mo Yan's Red Sorghum as a case study, this paper puts forward the translation strategies of the culture-loaded words from the perspective of the intercultural communication with Verschueren's adaptation theory as the theoretical basis. The author of this paper intends to prove the explanatory power of this theory, its feasibility and necessity so as to provide some effective ways to improve the translation quality of the Chinese literary works.
\end{abstract}

Keywords: Intercultural communication, Culture-loaded words, Literary translation, Adaptation theory, Red Sorghum

\section{INTRODUCTION}

The embryonic form of the adaptation theory originated from an article entitled as "Pragmatics as a Theory of Linguistic Adaptation" which was published in the International Pragmatics Association in 1987 by Verschueren. And he made a further explanation of this theory in his monograph "Understanding Pragmatics" in 1999, which indicates that the adaptation theory has become more mature. Adaptation theory believes that language use is a kind of "behaviour or social action"[1], and it is a process in which language users constantly make language choices according to the needs of the context so as to achieve the communicative purposes. Therefore, it can be said that the theory of adaptation is mainly about the co-adaptation between the choicemakings of language structures and the context. As for the adaptability of language, it mainly includes four research angles: contextual correlates of adaptability; structural objects of adaptability; the dynamics of adaptability and the salience of the adaptation processes. After the theory was put forward, it has received extensive attention of many Chinese scholars. Qian Guanlian was one of the pioneers who introduced the theory to China. He reviewed the theoretical framework of Verschueren's "Understanding Pragmatics" and believed that Verschueren's distinction between the pragmatics of language resources and the pragmatics of language use can not only inspire us to solve pragmatic problems, but also help us make more in-depth investigation on language phenomena [2]. Ge Lingling is one of the first domestic scholars who apply this theory to the translation studies. She explored the constraints and influences of the contextual adaptation on word meaning and believed that the choice-making of word meaning should adapt to different contexts so as to meet the needs of communication[3]. Based on the predecessors' exploration, this article analyzes the adaptation translation strategies of the culture-loaded words from the perspective of intercultural communication with these four perspectives as the research guideline and hopes to provide a feasible way for the translation of the culture-loaded words of the Chinese literary works.

\section{ANALYZING FROM THE PERSPECTIVE OF THE INTERCULTURAL COMMUNICATION}

\subsection{Imperfections of the adaptation to the contextual correlates}

The adaptation to the contextual correlates is one of the important aspects in the adaptative translation of the 
culture-loaded words in the intercultural communication. Verschueren divides context into the communicative context and linguistic context. The former includes the mental, social and the physical worlds of both sides of communication; the latter includes contextual cohesion, inter-textuality and sequencing. Once the contextual correlate is not properly adapted, it will cause the deviations in meaning of the source text and hinder the dissemination of the Chinese culture. For example, “海 茂子腔” is a kind of regional folk song in Shandong Gaomi. In order to achieve the readability or acceptance of his translation, "popular local opera" is selected by Howard at the expense of losing the local color or the cultural uniqueness of the source text. As we know, “海 茂子腔” is a local folk ballad that is sung in the daily lives rather than the opera of the music hall. In China, most culture-loaded expressions or words are interpreted with the adoption of free translation or domestication which impair the cultural features of the source text to some extent. Therefore, it is necessary for translators to find out the proper methods to keep a relative balance between the acceptance and the cultural feature of the culture-loaded words.

\subsection{The arbitrariness of the language structure}

The language structures in the translation process are the choice-makings made by the translator at the vocabulary, sentence pattern, and text level of the target language. However, in the translation process of the culture-loaded words, the language choices can hardly reflect the flavor of the source work in some cases for its strong local uniqueness. Therefore, its characteristics are inevitably lost. For instance, the Gaomi dialect is full of rhythm and connotation, which is really hard for the translator to retain the style or flavour and the meaning at the same time for the arbitrariness of the language structure and the cultural differences. Thus, the translation of this dialect is a real challenge for Howard to deal with for the arbitrariness of the language structures.

\subsection{Make the improper adaptations}

Dynamic adaptation is the core of the theory of adaptation. Verschueren believes that the process of the meaning generation is also the process of the coadaptation between language structures and context. Thus, the translator should make the language choices dynamically in the process of translation. Due to the cultural disparities between different countries, sometimes Howard can hardly make a good adaptation during the translation process, which results in deviation or improper choice-makings of the language meaning in the intercultural communication between the source work and the target readers. For example, “嘴里叫唤着: “亲 娘......再来几棍吧......再来几棍......”夰his is what $\mathrm{Yu}$
Zhan'ao said to my grandma to show his love for her. And Howard renders it as “"Mistress,' he shouted, 'a few more lashes... just give me a few more..."'Obviously, Howard's choice-making of “Mistress"(情妇) is too direct or straightfoward to display the subtle mental states of the hero at that very moment. At the same time, both the taste and the meaning of the source text are also deviated to some extent. In such a case, the translator should seek out effective strategies or methods to adapt to the characters' states of minds at that time and the language style of the text. This is also one of the current difficulties in the translation of culture-loaded words.

\subsection{Insufficient awareness of the intercultural communication}

The essence of translation is actually the intercultural communication. Thus, translators should keep a strong awareness of intercultural communication. On the one hand, the language features and the cultural uniqueness of the source text should be retained as faithful as possible, the readers' interests and expectations should also be taken into account on the other hand. For instance, Howard translated the local folk song of Gaomi-“武大 郎喝毒药心中难过 ...... 七根肠子八叶肺上下哆 嗦......丑男儿娶俊妻家门大祸......”, as:. ‘Wu Dalang drank poison, how bad he felt... His seven lengths of intestines and the eight lobes of his lungs lurched and trembled...'Although the meaning of the source text is clearly displayed, its language style and the sound pattern of the underlined part are both ignored. Thus, it can be seen that a higher degree of awareness of the intercultural communication should be paid much attention. Only in this way, can the readers' interests or expectations be met and the uniqueness of the heterogeneous culture be disseminated.

\section{ANALYSIS OF THE ADAPTATION TRANSLATION STRATEGY OF THE CULTURE-LOADED WORDS FROM THE PERSPECTIVE OF INTERCULTURAL COMMUNICATION}

Mo Yan's "Red Sorghum" is a masterpiece of the magical realism rooted in local culture and full of the oriental flavor. The author uses Gaomi dialect to show the rugged heroic qualities that have not been domesticated by civilization, shows the vitality, spirit and soul of the Chinese nation in her childhood, and makes people feel the power of human charm that has not been suppressed by morals and ethics [4]. At the same time, "Red Sorghum" is the first work of Mo Yan translated by Howard Goldblatt. It is also the most successful of his translations, and the most popular one in the English world. It fully demonstrates that the translator adapt to the norms of the target language, the readers' expectations and their cultural needs in the translation process. Now, let's 
analyze the translator's adaptation strategies from the four research perspectives of the adaptation theory so as to confirm the theory's explanatory power for the literary translation and promote the development of the Chinese culture.

\subsection{Adapt to the Contextual Correlates}

In the translation process, translators should not only adapt to the communicative context, but also to the linguistic context. Only in this way, can the connotation of the original text be faithfully conveyed and accepted by the readers. For example, in order to adapt to the features of the characters of the work, Howard translated“恋儿” in the original work as "Passion" by free translation. "Passion" is the servant of my grandma, and later has an affair with "my grandpa". By choosing the word "Passion", the translator vividly showed the character's personalities to the readers. After describing how the overseer had beaten Uncle Lohan with a cane repeatedly, he still had a "calm smile" on his face. The translator creatively chose "enigmatic grin" (inexplicable smile), which adapt to the cruel, barbaric and even abnormal character of the Japanese overseer. In the following, let's see another example to explore the translator's cultural adaptation in his translation:

For example: “他确实是饿了, 顾不上细品滋味, 吞了狗眼, 吸了狗脑, 嚼了狗舌, 啃了狗腮, 把一碗 酒喝得罄尽 [5]”. Howard translated it as “It was delicious, and he was ravenously hungry, so he dug in, eating quickly until the head and the wine were gone[6]". Mo Yan here uses meticulous and exaggerated techniques to describe Yu Zhan'ao's vivid behaviour of eating dog meat, from which we can also perceive the protagonist's rough character. Taking the differences in the cultural connotation of "dog" between China and the West as well as the readers' mental states into account, the translator made appropriate adaptations and choice-makings. He creatively chose the domestication strategy and simplified the underlined part into "eating quickly until the head and the wine were gone". Although the expression effect has been weakened to a certain extent, the translator maintains a relative balance among the faithfulness of the source text, the readers' acceptance and the cultural differences. As Howard once said, "I love the tension between creativity and fidelity, even the inevitable compromises" [7].

\subsection{Adapt to the Language Structures}

Translator's adaptation to the language structures can be analyzed from the adaptation and choice-makings of the code and style on the macro level and that of the utterance-building ingredients on the micro one. For example, in “Red Sorghum” Yu Zhan'ao said, “谁是土 罒? 谁不是土匪? 能打日本就是中国的大英雄。老子 去年摸了三个日本岗哨, 得了三支大盖子枪。
你冷支队不是土匪, 杀了几个鬼子? 鬼子毛也没 揪下一根。[5]” Howard translated it as “Who's a bandit? Who isn't a bandit? Anyone who fights the Japanese is a national hero. Last year I knocked off three Japanese sentries and inherited three automatic rifles. You're no bandit, but how many Japs have you killed? You haven't taken a hair off a single Jap's ass!'[6]" This sentence is what Captain Leng said to Yu Zhan'ao to persuade him to join the guerrillas rather than to become a bandit. Yu Zhan'ao thinks that it doesn't matter which team he joins, the key is to see how many enemies have been eliminated. The sentence is very concise and full of the colloquial flavor of the Gaomi dialect. The translator's choice-making of "Jap" (short for Japanese), "ass" (derogatory and vulgar), and "take a hair off" (spoken language) shows that Howard actively adapts to the language characteristics of the original text and reproduces it in the target language.

\subsection{Adapt to the Dynamic Principle of Translation}

In order to achieve an effective dissemination of this work, Howard make dynamic adaptations in his translation process. First of all, from the choice-making of the version, Howard Goldblatt chose the Chinese version of "Red Sorghum" which was published by Hongfan Bookstore in Taipei in 1988. The deletion of this version is manifested in the ideology. Almost all the sensitive words such as, the Communist Party, the Kuomintang, the Eighth Route Army and Chairman Mao have been deleted, which shows that the translator's choice-making before translation has fully adapt to the ideology and reading expectations of the Western readers. In the following, let's discuss the translator's dynamic adaptation with the examples. The first is: “父亲听到奶 奶说: “买卖不成仁义在么, 这不是动刀动枪的地方, 有本事对着日本人使去”[5]. The translator translated it as: "Father heard Grandma say,'Even if you can't agree, you mustn't abandon justice and honour. This isn't the time or place to fight. Take your fury out on the Japanese.'[6]” In this sentence: “江队长转怒为笑, 说: “余司令, 您误会啦, 我们八路军绝对不从朋友碗里抢 饭吃, 咱们是买卖不成仁义在 [5]”. The translator translated it as: “Commander Jiang's look of anger quickly gave way to a smile.'You've got me all wrong, Commander Yu. We'd never steal food from a friend's bowl. Just because we can't make a deal doesn't mean we're not on the same side.'[6]" As we can see that the underlined part of these two sentences are the same, but it is rendered differently for the translator's dynamic adaptations. In the first sentence, it implies that although Yu Zhan'ao is reluctant to join the guerrillas and share his weapons with Captain Leng, they are both justified and taking great honor in fighting against the Japanese. In the second one, it refers to the fact that these two characters are also friends that on the same line. 


\subsection{Translator's Salience in the Processes of Adaptation}

In order to enhance the effect of intercultural communication of the Chinese literary work, translator should keep a high degree of salience in the process of adaptation, which is a essential prerequisite to retain its language style and achieve the translation purpose. The actual language choice-makings are the manifestation of the translator's different degrees of awareness of in the process of translation. From Howard's language choicemakings, let's analyze his degree of salience in the translation process. First, Howard puts “爷爷与她总归 是桑间榉上之合...... [5]" as "So she and Granddad were adulterers...[6]". The idiom of “桑间兴上” comes from "The Book of Rites", which means the place where young men and women had a tryst and sang love songs. Mo Yan used this to euphemistically indicate the immoral relationship between Yu Zhan'ao and Dai Fenglian. Taking the target language readers' familiarity of the idiom and their attitudes towards sex into account, Howard Goldblatt adopted the strategy of domestication and chose the term "adulterers" straightforwardly. The connotation of the original text is successfully conveyed to the reader. Although the choice-making of the translator is too direct, it adapts to the contextual realities of the heroes and heroines, i.e. they are not bound by the traditional ethics, and are brave enough to pursue their own happiness. It can be seen that the translator has maintained a high degree of salience in adapting to the culture of the source text and the effectiveness of the communication. Howard Goldblatt spreads the heterogeneous culture to the greatest extent within the scope of the target readers' acceptance, which not only meets their expectation of the source language culture, but also disseminate the source language culture to a wider range.

\section{CONCLUSION}

This paper analyzes Howard's translation choicemakings from the four research perspectives of adaptation theory. Howard Goldblatt's English translation of "Red Sorghum" has been analyzed comprehensively, from which we can see that the translator's adaptive choice-makings in the translation process are made from many aspects. In addition to adapt to the language or cultural characteristics, the differences between the source language and the target language, the mental features of the characters in the novel, the author's intention, the readers' acceptance or their expectations are all considered by the translator in his language choice-makings. However, the imperfections do still exist for the cultural disparities or the translator's pursuit of his translation purpose. From our investigation, it can be concluded that a multi-dimensional adaptation and proper choice-makings is the prerequisite of a successful intercultural communication.

\section{REFERENCES}

[1] Verschueren, J. Understanding Pragmatics[M]. Beijing: Foreign Language Teaching and Research Press, 2000.

[2] Qian Guanlian. Pragmatics: A Unified Coherent Theoretical Framework-A Review of How to Understand Pragmatics by J. Verschueren. [J]. Foreign Language Teaching and Research, 2000, 32(03): 230-232.

[3] Ge Lingling. On Contextual Correlates of Adaptability and its Constraints on Word Meaning.[J].Chinese science \& technology translators journal, 2001,14(04): 27-29+39.

[4] Tan Dingsha. On the Common Character Connotation of Mo Yan's Red Sorghum.[J]Journal of Nanchang Institute of Education, 2014,(02): 21$23+50$.

[5] Mo Yan. Red Sorghum[M].Beijing:The Writers' Publishing House, 2013.

[6] Mo Yan. Red Sorghum [M].Translated by Howard Goldblatt. London:Arrow Books, 2003.

[7] Howard Goldblatt. The Writing Life $[\mathrm{N}]$.The Washington Post, 2002,4(28). 